\title{
SB 125
}

. W62

Copy 1

THER JONATHAN" SERIES-NO, 8
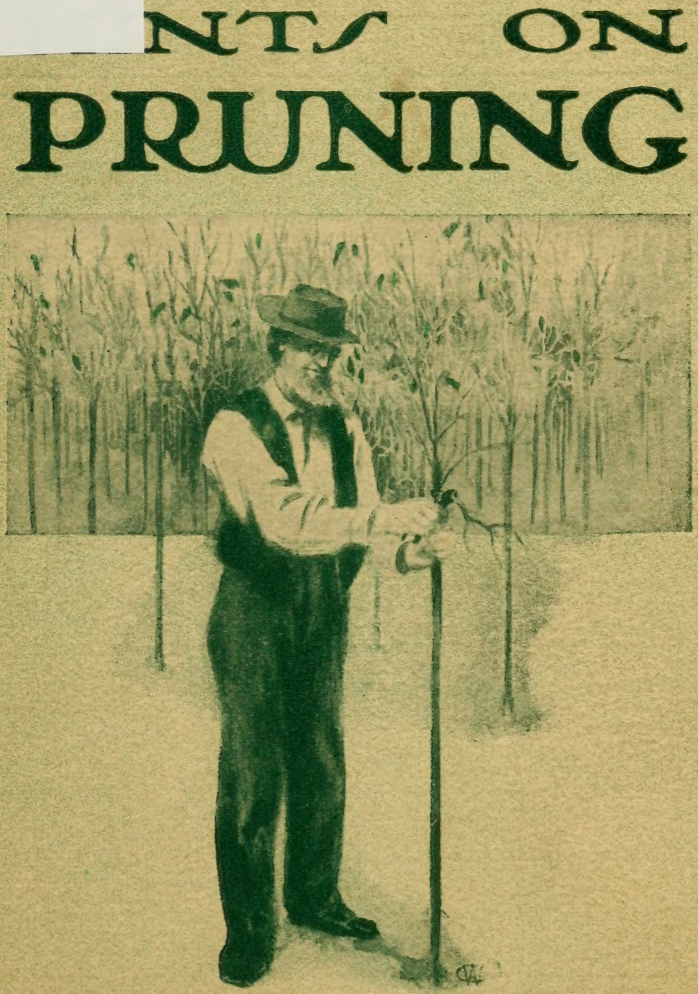

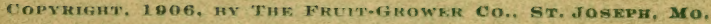




\section{"Bro.Jonathan" Series of Fruit Books}

Copyrighted and published exclusively by The Frult-Grower Company, Saint Joseph, Missourl.

This is a series of booklets published by The Fruit-Grower Co., St. Joseph, Mo., on different phases of frult culture, which are intended to help those engaged in the purguit of horticulture. All books are 111 ustrated.

No. 1- "Propagating Trees and Plants."-Describes the process of budding, grafting, layering, etc. It is by Prof. W. L. Howard of the University of Missouri, with protographs by F. H. Favor, of the same institution.

No. 2- "A Treatise on Spraying."-By Prof. J. M. Stedman, entomologist of the Missourl Experiment Station. Many of the most destructive insects are shown, with full directions for combating them.

No. 3- "How to Grow Strawberries."-By Dr. J. C. Whitten, professor of horticulture of the University of Missourl. It treats of growing Strawberries as a commercial crop or for home use

No. 4- "The Home Garden."-By Prof. Howard and Mr. Favor. It tells how to make hotbeds, colderames, etc.; how to handle them to the best advantage. The more common garden vegetables are discussed, together with some which are too often neglected

No. E-"Packing and Marketing Fruits."-By Prof. F. A. Waugh, of Massachusetts Agricultural College. This book tells about the correct times for picking different fruits, describes different packages used in which to market them.

No. 6-"A Book About Bush Fruits."-By Prof. A. T. Erw'n of Iowa Agricultural College. Treats of blackberries, raspberries, etc., with methods of culture: also gives recipas for canning and preserving.

No. 7- "Growing Grapes."-By E. H. Riehl, Alton, Ill. Mr. Riehl is a successful commercial grower, and discusses varieties, modes of training, etc.

No. 8- "Hints on Pruning."-By. Dr. J. C. Whltten. The pruning of different kinds of fruit trees and plants is discussed, with reasons for the methods recommended.

No. 9-"Apple Culture, with a Chapter on Pears."-By Dr. J. C. Whitten. This is intended to be a booklet for the practical man who wants to know how to get some good from his orchard.

No. 10-"Success With Stone Fruits."-By Prof. F. A. Waugh. The different stone fruits are treated, with lists of best varleties of each. Methods of planting, pruning, etc., are discussed for each class.

These Booklets Will Be Sent Postpaid for

\section{5c Each or Five for One Dollar}





\section{HINTS ON}
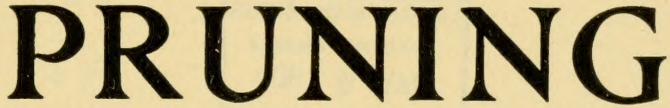

Some Suggestions Which Will be Found Helpful in Shaping and Training Fruit Trees and Plants and Ornamental Shrubs.

\section{By J. C. WHITTEN}

Professor of Horticulture, University of Missouri

PUBLISHED BY THE FRUIT=GROWER COMPANY SAINT JOSEPH, MISSOURI 




$-y^{2}-3$ 


\section{Brother Jonathan}

Series

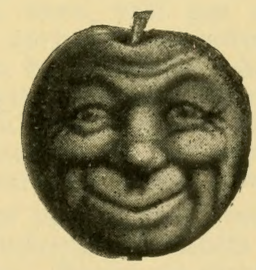

Booklet No. 8 



$\sqrt{2}+x^{2}$ 


\section{Introduction}

There is perhaps no more interesting and fascinating phase of horticultural work than pruning trees and plants. A plant is a plastic, responsive, changing, living organism which is affected by everything which we do to it. We cannot remove a single part of it without the parts which remain being affected by this removal. The removal of a branch powerfully affects the development of the branches which remain; the shortening of a limb modifies greatly the character which will be assumed by the parts of this limb which are left on the tree. A plant is capable of being shaped or moulded by pruning. He who prunes, then, will get results. Whether these results are fortunate or unfortunate, results at least are sure to be obtained. A plant is sure to respond to everything which we do to it. It is by pruning, and then watching and studying the results which will be obtained, as the plant grows, that the intelligent horticulturist learns how to prune.

Pruning cannot be learned from books. It must be learned by studying the habits of plants and the results of pruning. Books on pruning can, however, give one ideas which will enable one more readily to learn how to prune when he comes to do the work. If one desires to learn how to prune, it is highly desirable to read what has been written upon the subject in horticultural books and horticultural papers. This reading should not be done with the expectation that when it is finished the reader will know how to prune, and that the book may be permanently closed. One should read with the idea that it may give him a starting point in the practical operation of pruning, and that it will enable him the more quickly and the more accurately to interpret the results which he obtains by the work of pruning it- 
self. One may read a chapter on pruning and then go to the orchard and prune a tree, bearing in mind what the book said. He may then watch his tree grow for a season and then read again the same chapter. If he has lived, meantime, in sympathy with his tree, and if the written chapter is worth readirg, he will get more out of the second reading than he did from the first. This is because he is able to associate with the story which the book tells, the story which the tree reveals of how the pruning has affected its growth.

If the writer of this little book can do no more than to impress upon the minds of readers the fact that the book is useless unless the reader associates its suggestions with the actual experience of pruning, he will have accomplished something at least. The more one prunes, and studies the results of pruning by observing the trees themselves, the more helpful will the suggestions in books become. The writer has profited much by the suggestions made by others concerning pruning. Our horticultural papers, experiment station bulletins, books on horticulture and other literature on the subject teem with helpful material; every successful fruit-grower of his acquaintance has been his teacher; the trees which he has pruned, however, have been the chief interpreter, of the true meaning of all these helpful suggestions. If the readers of this little book are led by it to a clearer study of their trees, the book will have fulfilled its purpose. 


\section{Some General Obserbations}

\section{on Pruning}

It is comparatively easy for the skilful horticulturist to prune a tree so as to secure the desirect results. It is a very difficult matter for him to tell others how to prune trees in general. There is perhaps no other phase of horticultural work in which it is more difficult to formulate definite principles, or to give specific directions, then in pruning. If each tree were just like every other tree of the same variety, and was growing under just the same conditions, it might then be possible to give dogmatic rules for pruning. As a matter of fact, no two trees are just alike, and consequently no two should, or could, be pruned in just the same way. Each tree presents its own peculiarities of form and growth, and should be pruned in accordance with its own needs.

The above facts are in no wise discouraging to the fruit-grower. They do not signify that there is no such thing as rational pruning. On the other hand, these facts go to show that rational common sense must be used in pruning; that the operator cannot succeed by going at it in an unthinking manner, blindly following some dogmatic rule. It puts the work on a plane of intelligent procedure, where mind, judgment and knowledge must be employed in adapting the work to the needs of each individual tree. It renders the operation worth the while of the intelligent man-makes it an intelligent pursuit, rather than a monotonous drudgery.

In order to make some of the above statements more concrete, suppose we go to the orchard with a skilful fruit-grower. In pruning the first tree, he finds a single branch which he thinks should be re- 
moved. It is not needed by the tree; it is in the way; he prunes it out. The tree, he tells us, is now well pruned. We go to the next tree in the row. It is of the same variety and was planted at the same tıme as the first. We look for a similar surplus branch. It is not there. This second tree has not the same number of branches as the first. Its branches do not grow in the same position, or in quite the same relation to each other. What shall be done? After looking this tree over, the fruitgrower cuts out a branch. It occupied an entirely different position from the branch which was cut from the first tree, and the fruit-grower gave an entirely different explanation of his reason for removing it, from that which prompted him to remove the previous branch. He now remarks that this second tree is as well pruned as the first. Still, after being pruned equally well the two trees are not alike. One may tell them apart as easily as he can distinguish John from Henry. Where is the fruit-grower's rule for pruning?

While pruning cannot be reduced to definite rules, which will apply definitely to each individual plant, there are so-called "systems" of pruning the various species of plants which mean something more or less definite. In grape pruning there are in this country the upright and the drooping systems. In ornamental trees and shrubs there are the natural forms and the formal topiary work, which consists of giving the plants formal or fantastic shapes. In European countries especially, one is struck with the formal methods of pruning, or rather training, fruit trees, which is in contrast with the more natural form which similar trees are given in this country. Some of these differences in ideal are purely a matter of taste, while others are employed to suit a certain definite purpose, or to 
adapt the plant to given surroundings or environment.

The fruit-grower who has observed fruit trees in the Atlantic coast states and in the Central West cannot fail to be struck by certain fundamental differences in the shape of fruit trees, and the manner in which they are pruned in these different sections. In the East, fruit trees are generally given high heads, while in the Central West they are headed low. In the East, the trees are usually pruned with somewhat open heads, while in the West the heads are far more dense and compact. These differences are mainly due to an attempt to adapt the trees to the climatic conditions of each section.

Climatic environment governs to a marked degree the shape of plant which will prove to be best suited to a given locality, and consequently is largely responsible for the ideal which is carried out in a given section of country. The amount of bright sunlight, the humidity of the atmosphere, the prevalence of severe or drying winds, all go to affect the method of pruning.

In the maritime climate of the sea coast region, high, open heads are desired to admit sunlight and air. In this section, where more or less foggy weather prevails, the fruit needs sunlight to develop properly and to take on good color and good flavor. In the continental climate of the Central West, with practically no moisture screen in the atmosphere, compact heads to the trees admit sufficient surlight. Here, in fact, open heads often admit too much sunlight for the good of the tree, and sun scald of the trunk and main limbs may result.

In a dry atmosphere, with bright sunlight, and particularly if drying winds prevail, low, compact heads oppose in a measure too much evaporation of 
moisture from the parts of the tree, while in a humid climate no such precaution is necessary to protect the trees from rapid drying out. In a very humid climate, high, open heaas, to admit of a reasonable degree of dryness, affords a more congenial atmosphere for the parts of the tree. Strong winds unfavorably affect high, open heads. They strain the trees, break off the limbs and shake off the fruit prematurely. Low, compact heads break up the force of the wind tend to relieve the tree from strain by affording less leverage to the wind, and oppose the shaking off of fruit.

The practice, prevalent in Europe, of training the limbs of fruit trees laterally, on a trellis or wall, much as we train grapes in this country, so that each main limb and its attendant fruiting twigs are fully exposed to sunlight and air, carries out in still greater degree the principle of the open head in the East. In the maritime sections of Europe the atmosphere is very humid. Not enough sunlight is secured, at times, for the best development and ripering of the fruit unless each branch of it is fully exposed to the sun. Securing sufficient sunlight for the fruit is not the only object sought in these methods of training, but it is one object.

There are many other general principles that underlie pruning, and the adaptation of it to different conditions. For instance, the open, high head generally opposes the development of fungous diseases, especially in a moist climate, and hence trees are generally pruned less dense in humid districts than in dry, sunny ones. To some extent also the ideal of the grower may enter into the choice of a method of pruning. These factors will be discussed more at length, however, in the following chapters, under the head of each individual kind of fruit discussed. 


\section{PRUNING THE APPLE.}

Pruning the apple tree may be said to begin at the time of shaping the young tree in the nursery. The one-year-old apple tree in the nursery usually corsists of a straight stem, or whip, without side branches. The following spring many of the lateral buds of this straight whip push into growth, forming rosettes of leavez, or branches, from the ground up. The nurseryman expresses it by saying that the tree "feathers out" from the ground up. In order to secure the branching system, or head, at the right height these lower branches which are beginning to push out leaves are rubbed off up to the desired height, so no permanent limbs may develop too near the ground. The branches which are left continue to grow, forming the head of the tree. The height of the head of the tree is determined by the height to which these young side branches are rubbed off. Some desire high heads and some prefer low ones. This is partly a matter of taste and is partly determined by the section of country, or climatic conditions, where the tree is to grow.

Generally speaking, low heads are preferred in the Central West, where there is much bright sunlight, or where drying winds prevail. Higher heads are usually employed in the sea coast region of the East, where there is less bright sunlight. Low keads shade the trunk and main limbs from bright s unlight and oppose sun scald in the West, where this trouble is likely to occur. Low heads are also favored in the Northwest, where severe winds tend to strain the trees if the $y$ are headed too high. Higher heads allow the parts of the tree and the ground under it to get sunlight, which in a humid climate opposes the development of fungous diseases. There seems to be a general tendency, the 
country over, toward the adoption of lower heads for apple trees.

If one-year-old apple trees are to be set in the orchard they usually consist of straight whips, as has been suggested. The pruning at the time of setting will be to simply cut back the tree to a point about six or eight inches above where the head is to form. The main branches will then be put out near the top of the whip which is left. The topmost oud which is left will generally tend to form a straight central trunk, or lexder. Occasionally a one-year-old apple tree may be induced to branch and form its head the first year in the nursery. This is especially true toward the southern range of commercial apple growing, where the seasons are long. If the one-year-old tree is well headed at the time it is set in the orchard it should be pruned about the same as a two-year-old tree.

A two-year-old apple tree should be well headed in the rursery. It will generally consist of a straight trunk and the recuisite number of main limbs at the time it is set in the orchard. At the time of setting it should be pruned by shortening the side branches somewhat. Since much of the root system is removed in digging the tree, it is necessary to cut back the limbs so they will not evaporate more water than can be talken up by the cut-back roots. On an average about one-half of the length of the limbs should be removed. The amount will vary with different trees from one-third to two-thirds. The lower limbs should be left longer and the upper ones shorter, if a central leader is to be established in the tree. If the leader is very much longer than the limbs it should be shortened somewhat.

In case a tree is badly forked, that is, has two leaders, the fork should be corrected by cutting back one side of it. A forked tree may grow well for a 


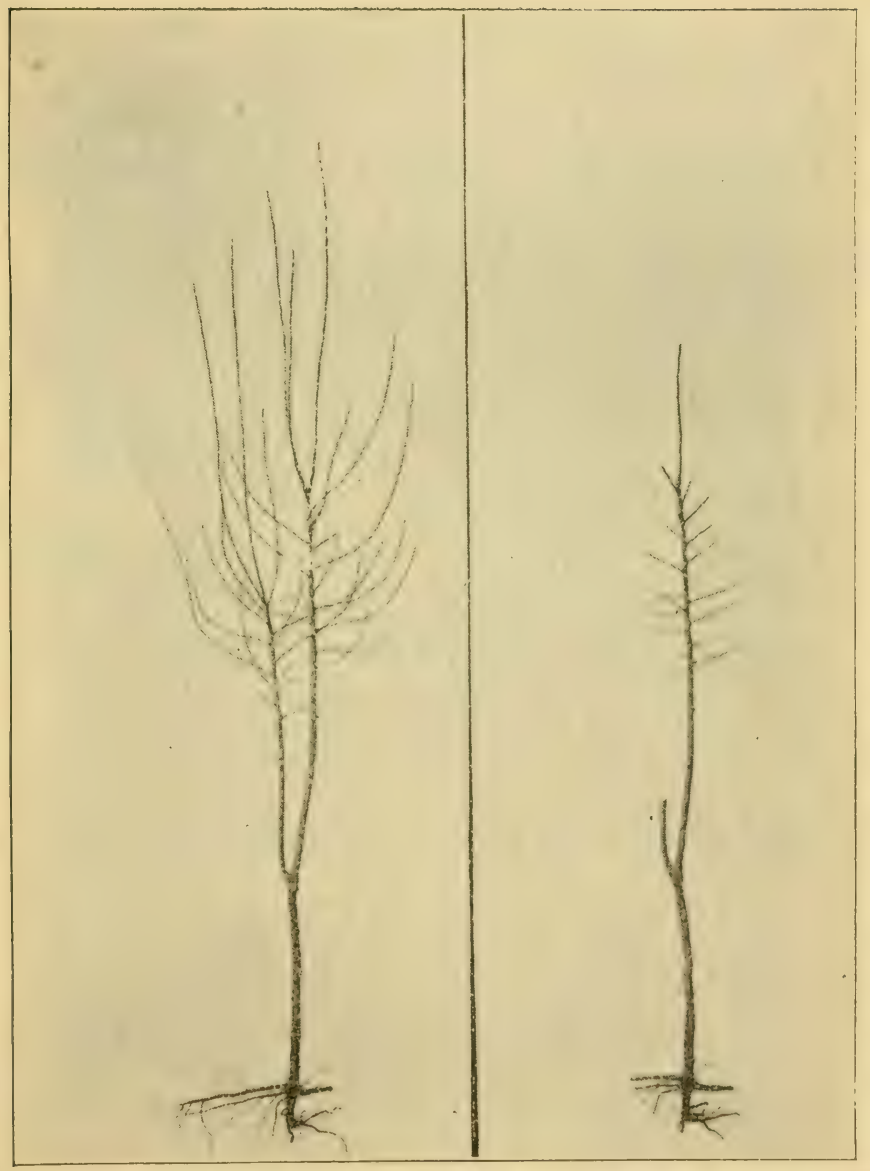

Correcting a bad fork at the time of planting out a two-year-old apple tree. 
time, but it is liable to split down when the tree is older and especially when it is loaded with fruit. One side of the fork may be removed entirely if this can be done without leaving too large a wound on the body of the tree. If there is danger of making a wound so large as to $d r v$ out and injure the leader which is left, it is better to cut back the surplus leader to a short stub having a few buds. This stub will put out side branches oftentimes and eventually become a part of the branching system of the tree. If it is in the way next year it may be removed entirely the second year after the tree has become well established. A large wound will heal better on a well established tree than it will if made at the tire of transplanting.

The root system should also be carefully pruned. First, any broken, ragged or badly bruised ends of roots should be pruned back to where the wood is in good condition. In digging the trees it is quite common that ragged wounds will be left where the roots are cut off. A ragged wound will not heal so readily as it vill if the root is cut with a smooth cut. In shapirg the roots a sharp knife should be used to make smooth cuts. If any root is unusually long it should be shortened so it will not have to be bent to get it into the hole where the tree is to be planted.

It has been thought by some that it was best to make the cut on the lower side of a main root when cutting it back. In order to accomplish this it is necessary to hold the tree so the trunk will hang down, leavirg the under side of the roots upward, so it can be cut on the lower side. It was argued that new roots are often emitted from the cut surfaces made at the ends of the main roots, and that these new roots will form more readily if they can 
be put out from below than if they must form from a cut on the upper side of a root.

Experiments at the Missouri Experimert Station seem to indicate that there is no advantage in following this practice. A number of trees have been planted for comparison on several occasions. Part of them had their roots pruned so all the cuts were on the lower side of their roots. The others were pruned so all cuts came on the upper side of the roots. The latter is the more convenient, as it enables the operator to hold the trunk of the tree under one arm while he cuts the roots of the tree from the upper surface.

An examination of the trees whose roots were pruned by either method showed that new roots were produced as freely from those which had the cuts on the upper surface as they were from those where the cuts were on the lower surface. Many of the new rootlets were put out from the sides of the main roots, anyway. Where the new roots were put out from the cut surfaces they started sooner, on an average, where the cuts were on the upper surface. If there was any advantage at all it was in favor of the trees whose roots were cut on the upper side.

This fact seemed to be explainable on the ground that the soil settled down firmly onto the cut surfaces which were on the upper sides of the roots, while in some cases it settled away slightly from the cuts which were on the lower sides. In carefully taking the soil away from the roots after they had begun to make new rootlets, it was found that these new rootlets started most readily where the soil came in close firm contact with the roots. The weight of the soil caused it to settle tight against the upper surfaces of the roots. In some cases, however, it settled down away from the ends of the 
roots where the cut was on the lower side, leaving a slight air space under the cut. In such cases new rootlets vere slow in starting. The wood of the cut ends cid not die back as a rule in cases where the cuts were on the upper sides, as moisture could pe taken in through the wounds which were in close contact with the soil. Where the cuts were below the cut ends dried out somewhat in many cases, because the soil did not come in close contact with the cut ends.

In addition to cutting back the main roots to a proper length, or to where the wood is sound and unbroken, it is also necessary to prune the fibrous roots somewhat. If the fine rootlets have dried out in shipment or in handling after the trees are dug, it is best to prune out all the dry. dead rootlets. If all the fine rootlets are dry and dead they should be cut off close to the main roots. Dead rootlets do no good on the root system, and they may do harm. One of the greatest dangers from leaving any dead rootlets on the tree is that they prevent the soil from coming in close contact with the live roots in planting. As soon as the rootlets dry out and begin to die they become harsh, stiff and begin to curl up. This makes a springy mass of fibres surrounding each main root. These curled, springy rootlets keep the soil from coring in contact with the roots. Even if the rootlets are not dry and dead, they may be shortened somewhat so as to allow the soil to be the more readily worked in among the main roots which remain.

This should not be construed to mean that it is a matter of indifference whether or not a tree has all of its rootlets dry and dead when it is planted. The writer prefers to have fresh rootlets in abundance. If they are dead, however, it is better to remove them and have them out of the way than it is to 
leave them to rot and die on the tree after it is put in the ground. In fact, it is being learned that it is not necessary to have such large and abundant root systems as was formerly supposed.

Any diseased parts should also be cut from the roots before the tree is planted. If a root system is badly diseased it is best not to plant the tree. It may, however, have minor knots on the smaller roots and still be a good tree, providing these parts can be cut away without injury to the root system. Occasionally a root gall, knot or wound may exist on a small root, which when cut away will leave a good tree. Any tree whose roots show injuries or diseases which cannot be pruned away without injury to the root system should be discarded.

It will be seen from the above that pruning at the time of planting the trees in the orchard consists of proper shaping of the root system and of giving the top or head of the tree the right form. In pruning the top one should keep in mind two things, to cut back enough of its wood to reduce evaporation so the cut-back root system can sipply enough water and to shape the foundation for the future branching system of the tree.

Subsequent pruning should consist in keeping the tree symmetrical, in regulating the density of the branching system to suit the particular climate, to remove any dead, diseased or broken parts and to control, so far as pruning may, the fruitfulness of the tree.

In continental climates, such as the Central West, where a dense head is to be maintained, many of the best growers prefer to establish and maintain a central trunk, or leader, around which the main limbs are symmetrically arranged. In order to maintain this leader it is necessary to correct each year any forks which form in it. If two buds start into 
about equal growth in spring they may form a fork. This may be corrected by pinching out one of these buds as soon in spring as the fork is observed, or the trees may be allowed to grow during the summer and one side of the fork cut off the following winter. In order to enable the leader to $k e \in p$ in the ascendency it is also necessary to prevent any of the side limbs from outgrowing it and making a second leader. In order to accomplish the latter purpose it is best to shorten any excessively long limbs by cutting them back to the desired length in winter.

While it is perhaps best to allow the tree to carry all its limbs at the time the tree is planted out in the orchard, some of them may require thinning out a little later, after the tree is established. A goodly number of branches may be beneficial at the time of planting the tree in the orchard. In a sunny climate especially they will put out leaves which will help to shade the trunk of the tree until it becomes established. These leaves will also elaborate plant food which is brought up as crude sap from the roots, and so secure a stockier growth of the tree the first year than would be secured if the branches were thinned out at that time. The permanent side limbs should not all be allowed to form at the same point on the trunk, but should be ranged on the trunk some distance apart, so they will not crowd and split when they become much thickened. If the tree carries more side branches at the time of planting than it will need permanently, the surplus ones may be thinned out from time to time. Often the first thinning may begin the first winter after the tree is planted in the orchard.

In thinning out any of the side branches which were allowed to grow for a time after the tree was planted out, it is well to remember that in a sunny 
climate especially care should be taken not to open up gaps in the head of the tree which will expose the trunk to bright sunlight and sun scald. This is especially important in the case of branches on the south side of the tree from which the most sunlight is received. Often a limb may be removed from the north side which it would be unsafe to remove from the south side. If the removal of a surplus limb threatens to let in too much sunlight the limb may for the first year simply be cut back, say to one of its lower side shoots, and then removed entirely the following year. This cutting back gives opportunity for the adjoining branches to push out new growth which will fill the gap made in shortening the limb. After the gap is filled the rest of the shortened limb may be removed.

In some cases the growth of the limbs on one side of the tree will be stronger than the growth of the limbs on the opposite side of the tree. In the West the north side of the tree tends to outgrow the south side. The northern limbs lengthen faster and spread out more at right angles to the trunk. This is because of the drying and heating effect of the bright sun on the south side. If allowed to continue the northern limbs may become so heavy as to tip the tree toward the north and still further expose the south side of the trunk or main limbs. On this account it is well to keep the tree symmetrical by shortening the longer north limbs each winter, and where possible thin them a little to reduce their weight. This keeps the tree in balance.

Some varieties of apple trees do not make many limbs in the nursery and often these are straggling and not well distributed around the trunk of the tree. Cutting back the limbs at the time of transplanting will often induce more limbs to form so as to close the gaps. Still further shortening the limbs 


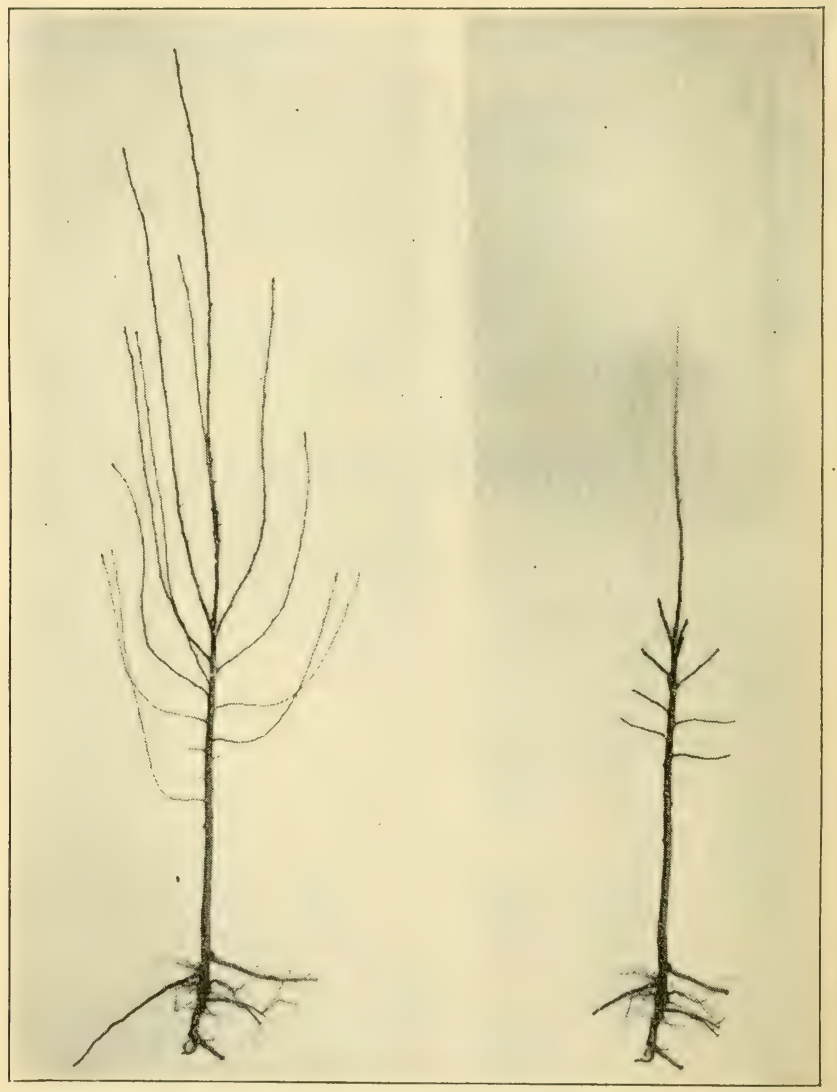

Two-year-old apple tree before and after pruning at the time of planting in orchard. 
during winter the first two or three years after the trees are planted out will also enable the grower to induce additional main limbs to form. Where it is desirable to induce better distribution of limbs it is well to bear in mind that cutting back to a bud next to the open side or gap will result in this bud pushing out a limb to fill the gap, while if the limb was cut to a bud which grew next to an adjoining limb the resulting branch would tend toward, rather than away from this limb.

It is best to remove surplus limbs while they are small, rather than after they become large. The removal of large limbs exposes parts of the bark of the tree to sunlight which has heretofore been shaded. The wounds heal far better if the limbs are cut when they are young. Adjacent limbs make more ready to grow to fill the gaps if surplus limbs are removed while they are young. In fact, the main limbs of the tree should be determined upon and established as early as possible after the tree is planted out.

In humid climates, where an open head is desired, it is often customary to shape the tree so its head will consist of about five scaffold limbs and dispense with the leader. If these main limbs are not already present when the tree is planted in the orchard they should be induced to form as early as possible by judicious cutting back in winter. After they are formed each year's pruning will consist of kecping the tree symmetrical by shortening any long limbs which tend to outgrow their fellows and in removing surplus limbs as fast as new growth outward tends to shade the smaller limbs within.

In almost any climate those who prune often cut away too much wood. It is best to look ahead and use such judgment in shaping the tree that the removal of large limbs, or of large quantities of wood 
at one time, will not be necessary. It is better to remove a surplus limb before it becomes a menace to the welfare of the tree than to remove it after it has gotten large and already injured the permanent limbs.

Much of the pruning of apple trees may be done in late winter or early spring. It is not best to prune when the wood is frozen hard as the wounds check, dry out, and do not heal so well as they do if the cutting is done on mild days. It is best not to prune during that season in spring when the wounds will bleed. This exudation of sap undoubtedly causes loss of food supply to the tree, and in addition it sometimes induces the development of organisms of decay in the wounds, so the latter do not heal so readily as they would if the cut were made before or after the bleeding season.

Pruning may be done at almost any time. Many growers prefer to go over their orchards in summer as well as in winter to attend to any pruning that any of the trees may need. The suggestion that trees may be pruned in both summer and winter does not imply that severe pruning and lots of it is desirable. On the other hand, if pruning is looked after frequently very little pruning at any one time will suffice. Dead or diseased parts should be removed whenever they occur.

In a general way it may be said that cutting limbs back somewhat in winter often induces a more vigorous growth of wood the following spring. If a part of the twigs is removed more sap is supplied to those which remain the following spring. The stored food, abundant especially at the base of the tree and in the roots, will be supplied to fewer buds if winter pruning has removed some of them. This results in increased wood growth. One may to some 
extent increase the vigor of wood growth of his trees by pruning in winter.

On the other hand, pruning in summer may result in less luxuriant wood growth. Shortening a growing branch at the right time in summer may stop its length growth and induce fruit buds to form upon it. In European plantations, trees trained upon walls or trellises, where labor is cheap, are usually pruned in summer to induce the formation of the desired number of fruit buds. They are also pruned in winter to thin surplus fruit spurs and to invigorate wood growth the following spring. There is an old adage, "prune in winter for wood and in summer for fruit."

Perhaps no reason may be given why summer pruning may be made to induce the formation of fruit buds further than to say that shortening a twig, at the right time, while it is growing, stops its length growth and turns the food to the buds which develop as fruit buds. Furthermore, removing twigs and leaves in summer lessens the amount of food elaborating surface which temporarily checks growth. Checking the length growth of a plant often results in the formation of fruit buds.

A tree which makes abnormally strong, vigorous wood growth does not usually produce much fruit until this vigorous growth is checked. Anything which tends to check the abnormally strong growth of a tree may throw it into bearing. A tree which is making abnormally weak wood growth may not fruit either. At times, however. a tree may meet with some accident which lessens its growth very much and the tree may set fruit so freely that it will bear itself to death. The grower will do well to acquaint himself with the amount of winter pruning or summer pruning which gives best results in his locality. 


\section{PRUNING THE PEAR.}

Much that has been said with regard to pruning the apple will apply in pruning the pear. The pear is closely related to the apple and grows with much the same habit. It produces its fruit on short spurs, in the body of the tree, or closely attached to the main limbs, like the apple. In this respect both the apple and the pear may be contrasted with the peach, which bears fruit on long whips of new growth. The pear is likely to make a more rapid and vigorous growth than the apple. Consequently it is less liable to need cutting back in winter to accelerate its wood growth.

Pears are grown as standards upon seedling pear roots or as dwarfs upon quince roots. Grown upon the pear root they reach normal or standard size. Grown upon the smaller quince they grow smaller, or become dwarf. The dwarf pears make a much slower and more stocky growth. They also come into bearing earlier. They are headed lower than the standards. In other respects than this the dwarfs and standards are shaped and pruned very much in the same manner.

The dwarf pear, on account of its slower wood growth, earlier bearing habit and tendency to set more fruit in proportion to its size, is liable to become weakened by over production of fruit. Its wood growth may be stimulated by judicious pruning back in winter and by thinning out some of its surplus fruit spurs when they become too abundant for the safety ot the tree. Most standards make sufficient wood growth, so that it is not usually necessary to induce greater wood growth by such cutting back.

Perhaps the most usual shape of the pear is to secure a straight, central trunk, or leader, around which are uniformly arranged the main limbs. In 
the beginning about five main limbs are usually allowed to form. Later other main limbs will be put out from the main trunk above. If forks form they should be corrected by cutting back one side of the fork as recommended for the apple.

The greatest drawback to successful pear culture is the blight, a bacterial disease which prevails to a greater or less extent in most parts of the country. This blight, called variously pear blight, fire blight, etc., usually appears in spring or early summer and is often quickly destructive. It sometimes causes the flowers and fruit spurs to die to such an extent that the season's crop of fruit is a failure. Sometimes the wood growth of the tree is largely destroyed for a year. In many cases the tree is killed or so extensively injured that it will never make a good tree. Pruning is done to some extent with reference to the blight. For this reason the most essential factor to consider in pruning is how may the operation oppose blight.

It is generally believed that the germs of blight enter the tree more readily in soft, succulent tissue, and that trees which are making a rank, sappy growth are more susceptible to the disease. This belief is emphasized by the fact that trees which are making slow growth in sod often escape serious injury from blight when rank-growing trees in cultivated soil in the same neighborhood are badly injured or even killed by the disease. Pear orchards on very poor soil often escape blight when trees in rich soils in the same neighborhood succumb to the disease. On the same tree the rank growing twigs or water sprouts are usually attacked sooner than are the short, slow-growing branches. When attacked, the disease progresses usually more rapidly in the rank, sappy limbs than it does in those which grow slowly. If a rank-growing limb begins to 
blight the disease usually runs down through the w.sole new growth, killing the limb quickly back to where the wood is old and firm. If a slow-growing limb is attacked by the disease it not only progresses more slowly, but the disease often finds the mature wood quite resistant of the disease, so it does not extend so far. Slower-growing trees are more liable to recover from the blight and to repair any damage done as soon as the next year's growth has time to assert itself.

In view of the above the better pear growers usually prune with the idea of avoiding any unnecessary rank growth. They are careful not to prune away enough in winter to induce rank sappy growth the following spring. They aim to avoid pruning too much at one time. Some of them do most of the pruning in summer, just after the blight season, which is usually early in the year.

Practically the only preventive of blight is to remove the blighted parts as soon as they appear and to cut out in early spring any blight pockets which have passed the winter in the wood of the tree. In most pear orchards the greater part of the pruning which is done consists of cutting out the blight. Whenever blight is observed it is best to cut out and burn the blighted wood. The cut should be made six or eight inches below where the blight shows, so as to be sure to get below the seat of the disease. It is best to disinfect the knife with carbolic acid or formalin after each cut is made, to avoid the possibility of inoculating the limbs with germs of blight that may cling to the knife blade. To disinfect the blade it should simply be wiped with a sponge soaked in carbolic acid or formalin after each cut.

The most important time to take precaution against blight, as shown by $\mathrm{Mr}$. Waite of the Department of Agriculture, is to cut out the winter 
pockets of the disease in late winter or early spring. In most of the twigs which blight in summer the disease runs down to where the wood is resistant and then stops. The germs of the disease generally die in this branch. For that reason most of the blighted twigs have no living germs of the disease when the tree goes into winter condition. Here and there, however, the disease continues to grow slowly in the wood until cold weather, winters over in a dormant condition, and pegins to spread again the following spring. If these few pockets of winter blight can be cut out before the tree begins growth in spring the chief source of infection from the disease may be gotten rid of before the disease can infect the tree in its flowers and new growth.

It is usually quite easy for the practiced eye to ciscern these winter pockets of blight. If a blighted twig shows a definite line of demarkation where blighted wood leaves off and healthy wood begins it is safe to consider that all germs of the disease are dead at that point. If there is no such line of demarcation, but if blighted wood blends so gradually into healthy wood that no one can draw a line where one leaves off and the other begins it is likely that living blight is passing the winter at that point. Sometimes blight pockets winter over in the main limbs. Usually its presence may be observed by the fact that the bark over such an area looks turgid and darker-colored than the normal. Where the bark shows a purplish color and looks swelled, as if the sap were trying to burst through, there is usually blight beneath.

If this winter blight is allowed to remain in the tree, exudations of a honey-like consistency will burst out just before or during the blossoming season. These exudations flow out in considerable quantity, as a rule. The exudation contains the 
germs of the disease. Insects feed upon these exudations and carry the germs of the disease to the tlowers and new growth on the trees, as soon as growth begins.

In order to prevent such infection the grower should go over his orchard in early spring just before growth begins, and on until the blossoming season and look for winter pockets of blight. All possible of such pockets should be cut out and burned before the exudations begin to flow. If any are missed they can eacily be seen as soon as the exudations begin to flow out. If these can be gotten rid of before the blossoms open there will bes little danger of blight, unless it is brought in from orchards where winter blight is not cut out. The growers of a neighborhood should be encouraged to cut out winter blight to avoid infection of their own trees and the trees of their neighbors.

Where the blight winters over in a small twig it is easy to cut it away and get rid of the source of infection. Where blight poskets winter over in the trunk of the tree or in large limbs the problem is more severe. It may be recessary in such cases to chisel out the blighted areas and paint the wounds with white lead ard oil paint. Wherever such areas are chiseled out the grower should examine them frequently to see if any exudations come out around their borders, where blight has been missed in chiseling out the diseased part.

\section{PRUNING THE PEACH.}

Among our cultivated fruits the peach is the one which usually receives the least pruning or general attention, yet it is the one which needs the most pruning. Its strong, thrifty growth, its manner of fruiting make it necessary for best results to remove a large amount of wood each year, and 
upon trees most carefully pruned are borne fruit of the finest quality. In all of the operations of pruning fruit trees it is necessary that the pruner should know where the fruit buds are located and their condition at the time of pruning. The ignorance of this could easily lead to the removal of all fruit buds and leave the otherwise productive tree perfectly barren for one or more seasons. And a knowledge of the condition of the fruit buds at the time of pruning will allow one to judge better as to the system of pruning. In the peach this is essential information to have. When there is good prospect for a full crop of peaches, the operation of thinning can be partially done by pruning. When all fruit buds are killed, advantage of this can be taken to get the head of straggling trees lower and more compact, by removing a large portion of the top. Let us look at a peach tree as it comes intd bloom and see where the flowers occur.

Our tree, we find, has the long slender twigs which formed last season covered with the delicate pink flowers. As a rule there are two flowers at each joint on the twigs, and they appear at almost every joint from the base of the twig to the very tip. Even the side branches have their share of flowers, and the little slender whips that formed last season in the center of the tree are also covered with blooms. The two flowers at each joint on the twigs, we find, are separated by a small bud that is showing a tip of a small green leaf. If we had looked at the twigs before the flowers opened we would have found three buds at almost every joint. The central bud is small, and much compressed by the large plump bud on each side of it. This central bud is a leaf bud, and as soon as growth starts will push out a cluster of leaves, or a new branch. The large plump buds on either side 
of the leaf bud, encloses a single flower, sometimes two, and from the great number of flowers on the tree, a great struggle for existence must take place between the fruit as it grows and approaches maturity. If all of the flowers on a tree in full bloom are left many will fail to set fruit, because of the inability of the tree to supply all with the proper amount of sap. Many will set fruit, but of these fruits many will fall to the ground before reaching maturity for the same reason. And when the fruit ripens there is only a small number of fruits compared to the great number of flowers which were on the tree, yet the tree may be breaking down with its load of iruit. To avoid this breaking down of loaded trees, to thin the fruit and lessen the struggle among each individual fruit for sap from the tree, and to maintain a properly shaped head on the tree, so that in future years a heavy crop of fruit will be produced, it is necessary for us to prune the trees. Every year the peach trees need some pruning, and during the early life of the trees, this pruning may be very severe. Let us now take up this matter of pruning, starting with the tree as it is dug in the nursery and made ready to set in the orchard or garden.

small or medium sized one-year-old peach trees are the best for general orchard planting, while the larger trees are very good, where only a few trees are wanted in the home orchard or garden. As these one-year-old trees are dug in the nursery, they have a straight central stem, with side branches at frequent intervals, close to the ground to near the tip. These side branches bear numerous buds located at short intervals from the base to the very tip. When growth begins, each of these buds will open and send out a new branch. Those close to the base will be shaded by the leaves on 

the outermost ones till they perish, while those. close to the tip, where full sunlight can be had, will develop long branches. If a young peach tree is allowed to go without pruning, at the end of the second year its branches will be very long and slender and give the tree such shape that it is in danger of being broken to pieces upon the production of its first crop of fruit. To avoid that injury, to get a dense close head, close to the ground, the young tree when it is made ready to be set in its position in the orchard must be pruned. The customary way of doing this is to remove all of the side branches back to the first bud from the central stem, and cut back the tip of the trunk which is lert fully one-third. This leaves a mere stick with a tuft of roots at the lower end. Some of these. roots will be more or less mutilated or broken. Cut the broken roots off just behind the break, making a clean, smooth cut that can heal over quickly. Any roots that are unusually long, should be shortened in to a convenient length. A generous amount of roots ought to be left since it is through the roots that the tree gets its water and food, and plenty of roots will enable the tree to take hold of the soil and start into growth better than where only a small root system is left. If the rootlets have dried out in shipping, they should be cut back to where they are alive. In some parts of the country it is the practice to cut the roots back as severely as the top, making the tree when ready for planting nothing more than a club. The tree is then planted in a hole made with a crow-bar. That system, while it has many advantages, and may prove a success in some parts of the country, does not give satisfaction in Missouri and the surrounding states. Our trees must have at least a small 
amount of the root system left in order to start the tree into growth.

The new growth on a peach tree is produced principally at the extremities of the wood formed during the past season. If the trees are allowed to grow at will, it is only a matter of a few years till all of the fruiting wood is far removed from the trunk of the tree. From the long, straggling branches thus formed it is difficult to pick the fruit and there is danger of the trees being ruined for future production, through their splitting and breaking under a heavy load of fruit.

\section{PRUNING AFTER THE FIRST SEASON'S} GROWTH.

To get the head closer to the ground, to control the amount of fruiting wood formed, and to maintain the correct shape of the tree, proper pruning must be done each season after the tree is set in the orchard. After the first season's growth of the young tree, pruned as above, it will be found that each of the short stubs bearing a bud has sent out a strong branch. During the early spring of the next season cut vack this new growth severely. The side branches should be shortened in such manner as to give the pruned tree a distinctly pyramidal shape. This can be done by cutting the lowermost branches to a length of five or ten inches, depending on their original length, and cutting the next branches above still shorter. Remove from the central stem about half of its length, leaving it about a foot longer than the upper branches. At the rext pruning, after the young trees have made two seasons' growth in the orchard, the same principle must be followed. Severe pruning needs to be given the young trees, making them take on as much of a cone-shaped habit as possible, During 
this second season many lateral branches will have formed on the main branches. Shorten these into two or three buds, and remove any which are weak or a€ad, cutting close to the main limb on which they are borne. Maintain a central leader in the tree; leave the lower branches longer than those above them, so as to give the tree a coneshaped head. 


\section{PRUNING THE BEARING TREE.}

After three seasons' growth the trees will have probably made a good setting of fruit buds, and the subsequent pruning must be done in such manner as to thin the fruit and maintain a correct shape in

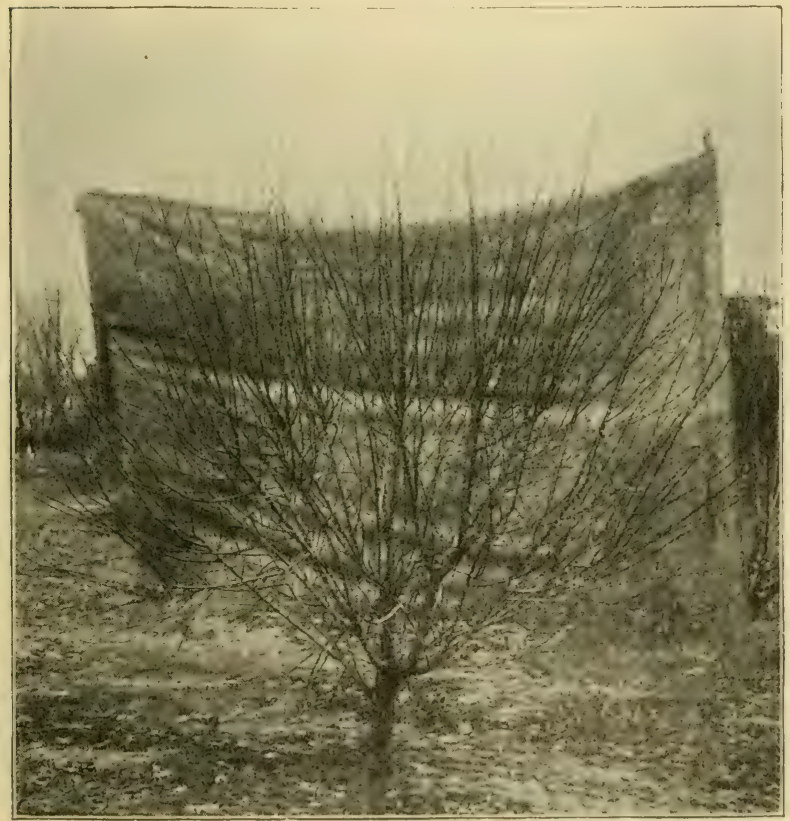

Fig. C.

Peach tree of bearing age, before pruning. 
the head, avoiding as much as nossible long straggling branches. Since the peach always sets many more fruits than it can bring to maturity, even ir the most favorable season, the removal of some of the fruiting wood during the work of pruning

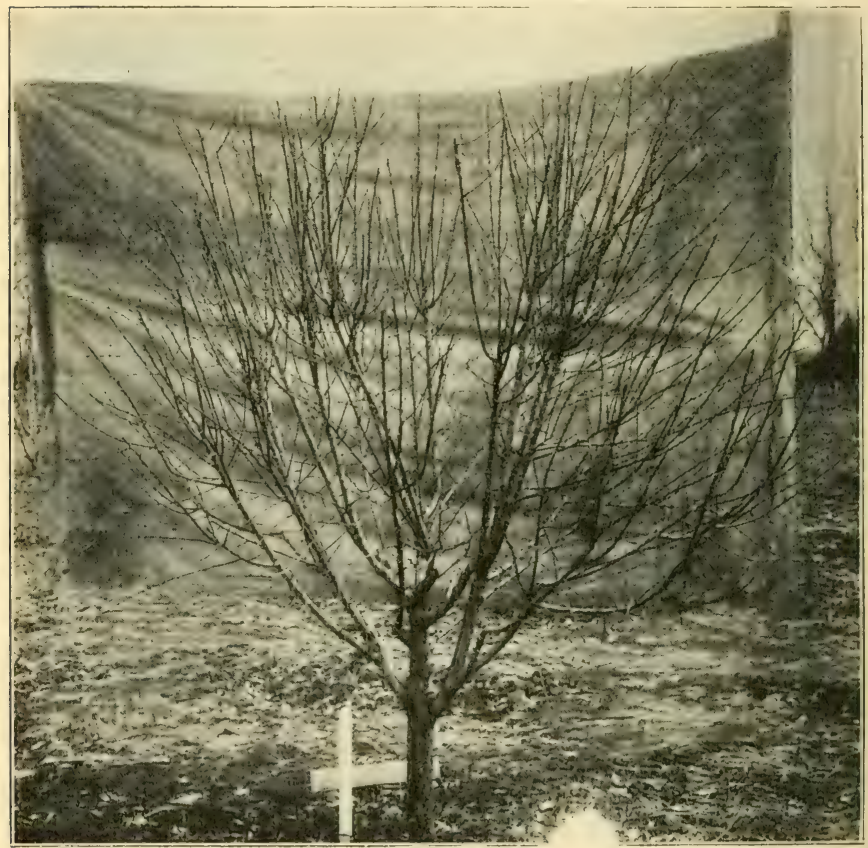

Fig: D

Peach tree, sime as $C$, prumed by cutting back and thinning out surplus twigs. Correct pruning under normal conditions. 
makes the remaining fruit all the larger and better flavored. The amount of wood which may be removed depends much on the experience of the grower and the condition of the fruit buds at the time of pruning. In cases where the fruit buds have all been killed more wood may be removed than where a full crop is promised. In general, where the fruit buds are in good condition, remove at least one-half of the central leader on the branches and shorten in the lateral branches in proportion. Although much wood will be removed in doing this, many fruit buds will be left and as many fruits form as the trees can mature. In fact it is often necessary to thin the fruit still more by thinning by hand later in the season.

\section{PRUNING WHEN ALL THE FRUIT BUDS ARE KILLED.}

In cases where the fruit buds are all killed by frost the manner of pruning may be somewhat different from that just given. The way by which one car tell whether fruit buds are dead or alive is by cutting them in two in the middle a few days after a freeze or frost which is suspected of having caused injury. If the buds are dead the interior of the buds will be dark colored. If examined within a day or so after a frost the buds may not have had time to become dark colored, but the frozen or dead buds will have a water-soaked appearance. Some fruit buds die everv year, and in making an examination of the buds several buds on a tree should be cut open in order to get a correct estimate of the number lost. The live buds, when cut open, instead of having a darkened interior, will be of a bright greenish cast and be more solid to cut through than those which are dead. 
After a careful examination of the peach trees, if it is found that all of the buds are dead, advantage may be taken of this tailure in a crop to get the trees headed lower and of a better shape. When several crops are borne in succession the trees will have become quite straggling in habit, even under the best system of pruning. To get them back, closer to the ground the main limbs must be cut short so as to leave only short stubs or spurs. The wood which formed last season is removed so that only six or eight inches of the base is left. All of the smaller twigs are cut out, and anv bad forks in the higher por-: tion of the head are corrected by removing or shortening one side of the fork. Where several branches come out close together the weaker ones should be removed and nothing but strong, vigorous branches left. Pruning in this fashion will remove the larger part of the wood formed during the last season, but from the spurs which are left there will spring many new branches to bear fruit on the following year, and the tree will be in better shape to carry a heavy load of fruit after this severe pruning.

It sometimes happers that not only the fruit buds on a tree are killed but the wood is badly injured by extremely cold weather of winter. Such injury can be told by the discolored appearance of the wood upon cutting through the bark. When such is the case the method of pruning must be even more severe than when the buds only are killed.

\section{PRUNING AFTER WINTER INJURY.}

It sometimes happens that it is necessary to cut a tree back so as to leave nothing but stubs of the large limbs, cutting off all the limbs smaller than a man's arm. Cutting back into wood two to four seasons old, or at least into wood which has a clean, 
smooth bark will put the trees into better condition than if the winter-killed wood is all left. This wood which is left will send out new branches from buds



H'ig. E.

Peach tree, same as ('. closely nrmned after serer. winter injury.

that have heretofore remained dormant, and the trees thus acquire an entirely new head as the result of the treatment. Good judgment is needed to 
tell just how far to cut back frozen trees in order to renew the top. It depends somewhat upon the age and vigor of the tree and also upon the extent of the injury. It is not possible to lay down any rule that will apply to all cases. It will be well to bear in mind the following suggestions. Cuttin back may be so severe that the remaining stumps will not sprout and the tree will die. The old stumps may have no active buds to push into growth. The older the wood the more difficulty there is in the tree sending out new branches and the more slowly it will start in spring, while the newer the wood the more quickly it will push out into growth. This method of heading in peach trees is practiced by many extensive peach growers every few years, simply to renew the vigor of the trees. In this way. strong wood growth can be promoted and the head of the tree kept closer to the ground, where it mav be more readilv managed. The lower heads are more easily nruned and sprayed and the fruit can be thinned and gathered at a smaller expense than on trees with high tops. Where the trees are cut back in this fashion in years when the wood is not frozen. there will form a very rank new growth, which will continue growing till frost kills the tips. To avoid this several long branches should be left at convenient places over the tree to use up much of the surplus energy of the tree. Sap will be forced into these long branches and used in the formation of wood on them, and the growth of the new shoots from the older portion of the tree will not be so rank nor continue into growth so late. These extra limbs can be shortened in the next season so as to maintain the proper head on the trees.

Upon the new growth formed the next season after severe cutting like this there may be a short 
crop of fruit, but the new head formed will be much more fruitful in following years than on trees which were not cut back at all or given only moderate pruning.

\section{PRUNING THE PLUM.}

The Japanese plum has much the same habit of growth as the peach. It thrives in much the same conditions as respect to soil and management. It should be pruned about the same as the peach, though perhaps not quite so severely. The directions given for pruning the peach will in the main apply with equal force to the Japanese plum. Even the long whips of new growth at the terminals often produce fruit buds the same as in the case of the peach and fruit buds will generally be produced in sufficient abundance if the trees are cut back enough in winter to induce a good vigorous wood growth the following year. This cutting back also helps to thin the fruit which sets in superfluous abundance as a rule.

The European plums and native American plums are pruned much the same as the pear and the apple. They are usually given a straight, central trunk, or leader, and headed low. The branches are kept from becoming too dense by thinning judiciously while they are young. Any limbs which cross, rub or crowd each other are relieved by removing the branch which is most in the way. Pruning should never be severe at any one time, as it may result in water sprouts or even in suckers from the root. The vigor of growth may be regulated to some extent by the amount of pruning back which is done in winter. If wood growth is so luxuriant as to oppose fruitfulness, the long whips of new growth may be shortened somewhat, which will result in the formation of short laterals which will later bear fruit. 


\section{PRUNING THE QUINCE.}

The quince is a small tree which makes naturally a straggling growth which it is difficult to prune so as to get a good-shaped tree. In fact, very little pruning is given it, as a rule. If neglected, however, it is liable to make many sprouts or water shoots from below and get too thick and tangled to be easily managed. Some pruning should be given it.

The quince should be headed low. It is small in habit and usually headed as low as will enable the grower to secure a definite trunk. Pruning consists of thinning out surplis limbs so as to maintain a manageable tree. It should not be pruned back enough to induce a very rank growth. Any limbs which cross or rub badly should be removed. It should also be kept symmetrical by shortening any long straggling limbs which tend to outgrow the others. Just enough pruning of this character is done to enable the grover to get at the fruit with convenience and to enable the fruit to get enough sun and air to mature vell.

If the tree makes long limbs which are rank it is sometimes advisable to shorten these sufficiently to induce them to make branches for fruiting and to secure a stockier growth of the tree. Shortening the long whips of growth judiciously usually induces the formation of laterals which will produce fruit buds at their tips. .

In pruning the quince it should be remembered that it is subject to fire-blight to about the same, extent as the pear. The same precautions which apply to pruning the pear to oppose blight will also apply to the quince. 


\section{PRUNING THE CHERRY.}

Generally speaking the cherry should be pruned less severely than most of our other orchard fruits. It makes new growth most readily from its terminal buds. Often the buds on the older wood are so inactive and dormant that they do not start readily into growth if the wood is cut back much. In this respect it is very different from the peach, which will start new growth readily from wood several years old.

Either one-year-old or two-year-old cherry trees are selected for planting out in the orchard. The trees are usually well headed as they come from the nursery. They are headed somewhat low, say from eighteen inches to three feet from the ground. At the time of planting in the orchard the trees are not cut back much. The active buds on the cherry are for the most part near the tips of the new growth. Toward the top of the main stem and at the terminals of the main branches there are a few large, fresh looking, active buds. These are capable of starting into active growth after the trees are set out. If the main branches are cut back much most or all of these active buds may be removed. If there are only a few such large active buds on each branch, the tree should not be cut back at all. If there are a half dozen or more on each branch the branches may be shortened so as to remove a few of the buds near the terminals. At most, however, the limbs of the cherry should not be shortened more than a few inches. If the limbs are abundant, and the root system so small that cuting back becomes necessary to avoid evaporation, it is urually better to thin out some of the limbs entirely than to cut the others back. What limbs are left on the tree should contain good active buds at their tips. 
In pruning the cherry subsequently it is well to remove as little wood as possible. Just enough cutting should be done to keep the tree symmetrical and to remove limbs which are crowding other parts of the tree. If a limb is to be removed it is well to cut it out while it is young. Old limbs should not be removed where it can possibly be avoided. Where old limbs are removed gum is likely to exude from the wound. The wounds on cherrv trees do not heal so readily as they do on most other fruit trees.

Much of the shaping of cherry trees may be done by pinching out surplus shoots while they are growing. If the twigs start to form an undesirable fork for example, it is often desirable to correct this fork by pinching back one of the shoots before it has made much growth. After the cherry tree reaches bearing age very little pruning will be necessary, except to remove any deac or diseased branches.

\section{PRUNING THE GRAPE.}

The grape is pruned more severely than any other of our fruit bearing plants. It has a tendency to produce a very rank growth and make so much wood that the vine could not possibly support well the fruit that would form if the vine is not greatly reduced by severe pruning. The grape is pruned every year and the pruning may be reduced to a more systematic and exact form than can the pruning of onr orchard trees.

In pruning the grape it is well to consider first the formation of the vine from the beginning. The vine is usually set in the vineyard when it is one or two years old. At that time it is best to cut it back so as to leave only about two buds on each of the one or two canes which the vine bore. This means cutting it back close to the ground, or so 
only a few inches of new growth of stem is left. The roots also may be shortened somewhat for convenience in planting.

The following season new shoots will form from the few buds that were left. Generally three or four shoots will be produced. These should be allowed to grow about at will on the ground. The first winter after planting in the vineyard these shoots should again be pruned. The pruning now will depend upon the system of training which is to be used.

There are two systems of training which are important enough to deserve mention here. They are the upright and the drooping systems. In the upright system a short stem is given the vine and the fruiting wood is trained upward on the trellis from this stem. In the drooping system a longer stem is used which reaches the top of the trellis and the fruitbearing shoots hang down. It will be observed that these two methods are opposed to each other in that in the former the fruiting shoots are supported in an upright position by the trellis, while in the latter the trellis supports the main stem and the fruiting shoots are allowed to hang down. Each of these systems has its modifications. Before discussing their comparative merits it may be well to outline the method of pruning by each system.

In the upright system a plain trellis of three or four wires is usually employed to support the vines. Posts are set in a straight line at necessary intervals along the row of vines to support the wires. The two end posts of each trellis are braced strongly, so the weight of vines on the trellis and the sagging of the vines will not cause the posts to tip in the ground. The posts should be about five or six feet high after they are set in the ground. The lower wire of the trellis is stretched along these posts and fastened to them about eighteen inches above 
the ground. The two or three remaining wires are stretched and fastened to the posts at intervals of about one foot apart above the lower wire. These wires, ranged in this manner, one above another, form the support for the vines.

The old stem of each vine does not usually extend above the lower wire of the trellis and sometimes it is kept back to a very short stump. This short stem, or stump, produces the new growth of the vine which grows up and is trained to the wires above. No matter how old the vine may be the wood above the old stem is frequently renewed, by pruning back, so the branches which cover the wires of the trellis are never more than two years old.

In order better to understand what is meant by statements made concerning pruning the vine it is well for us to understand, not only how the trellis is formed, but also to give technical names to the branches of the vine which are of different ages. A new branch which starts in spring and grows during the summer is called a shoot. After it has shed its leaves in autumn and become dormant it is called a cane, during the first winter of its age. After growth begins next spring, so the winter cane is more than one year old, it becomes an arm. The still older part of the vine, above the root system, and from which shoots, canes and arms may be produced, is called the main stem or stump of the vine. To restate, a shoot is a new branch from the time it starts from a bud in spring, until it sheds its leaves in the fall. It is a growing summer branch. A cane is a dormant branch, during the first winter of its existence, and up to the time it begins growth the following spring. An arm is a branch which is more than one year old.

The fruit is produced on shoots which start in spring from the buds of a cane which has just 
passed its first winter. The best truiting canes are those which are attached to wood only one year older than themselves. That is, of two winter canes, one of which comes from a dormant bud or the old stem, or from the root of the vine, and the other. of which comes from a branch only one year older than itself, the latter should be preferred in selecting canes to bear the following crop of itait.

In pruning during winter or early spring each vine should be reduced to two fruiting canes which are attached to wood only one year oldei than themselves. These canes should be shortened to four or five feet in length, according to the strength of the vine and the amount of fruit which it is considered able to carry. In addition to these two fruiting canes, two other strong canes should be selected (preferably from below the two fruiting canes), and cut back to short spurs, containing aboilt three buds each. The three buds on $\epsilon$ ach of these spurs are designed to produce shoots during the spring and summer which will be saved as fruiting canes when pruning is done the following winter. All the rest of the newer parts of the vine, ahove the old sten, including the parts of the vine which have produced the summer's crop of fruit, together with all surplu: canes. are cut away.

The winter pruning reduces the vine to two fruiting canes, about four feet long, whicil are to produce the coming fruit crop, and two short spurs which are to produce the wood which is to be sclected for the subsequent season's crop of fruit. Tha same branch is never allowed to produce but a sincrle crop of fruit, but is cut away during the winter following the production of its fruit crop. 'The aim in winter pruning is to provide for the coming fruit and for renewing wood for the subsequent year's crop-in 
other words to secure fruit for the coming spring and fruiting wood for the next spring afterward.

In some cases it will be found that these fruiting canes, when being pruned in winter, have sirle branches which pushed out while growth was going on in summer. In case they have side branches these should be pruned off. If they are weak branches they should be cut close to the main cane. If any of the side branches are strong they should be cut back so as to leave a single joint attached to the main cane. Many growers claim that better fruit is produced on a shoot that comes from the basal bud of one of these side branches than from a bud on the main cane itself. For this reason some growers attempt in summer training to induce the branches which are to become fruiting canes to make side branches freely during summer. This will be further discussed under summer training.

In selecting the two fruiting canes at the time of winter pruning the grower should be able to distinguish between those which are likely to produce the best fruit and those which are less well suited for fruiting purposes. In other words he should be able to recognize the difference between canes which have fruiting buds-buds which will produce shoots which will fruit freely and canes which, like water sprouts, will not fruit well. In most vines there will be canes enough so the pruner will have choice in this matter.

The best fruiting canes are those which have short nodes, or joints, and which have large, firm, well developed buds. They may not necessarily be the largest canes or the longest. They should be firm and well ripened and the closer together their buds are the better. Their bark should be bright, fresh and firm, never bleached. Usually they are crooked at the joints, giving them a zigzag appear- 
ance. This zigzag form means something. It is due to the fact that the more fully the bud at each node is developed and the more stored food there is in the joint the more the growth which forms below the next bud above is pushed to one side, thus forming a wide angle at each joint. The very filling up of the bud and joint tips the cane to one side above the joint, or pushes it away from the bud. If a cane has well-developed side branches it should be preferred, other things being equal. The development of short, stocky side branches indicates a strong cane.

Opposed to such cane is the rank growing water sprout. The water sprout may be larger, longer, and at first sight better looking to the casual observer, than the better matured and ripened cane. The water sprout has longer joints, that is a longer space between its buds. Such a cane is straighter, with hardly a suggestion of an angle or crook at the joints. Its buds may look large but they are looser and less well developed. Often such a cane is flattened at the joint instead of being full, round and plump. Often, especially near its outer length, it is more or less shriveled and the bark bleached and lighter colored. It put most of its food and energy into making length growth instead of filling itself up and maturing well. Such a cane should not be used for fruiting.

In cutting back canes for spurs those which are below the fruiting canes and which are vigorous and healthy should be selected. It is not necessary that they be attached to wood only one year older than themselves. They may come from the old stem or even from near the roots of the vine. It is desirable that they be selected from below the fruiting canes so that in pruning their growth for: fruit next year all the older wood which has fruited 
may be cut off above them. Since they are selected from new canes their shoots, which are to become the fruiting canes for the subsequent year, will be attached to wood only one year older than themselves. The fruiting canes of each winter then are those which were produced from the short spurs of the previous winter.

After the vine has been pruned as described above, we may expect each bud on the fruiting canes to send out a shoot in spring. As each shoot reaches several joints in length flower clusters form at the joints near its base. Each joint may produce about two flower clusters (sometimes four or five), and a corresponding number of bunches of fruit. At this time summer training, or summer pinching should begin. Let us see what it consists of.

Summer training is for the purpose of properly distributing the vine over the trellis as it grows during the summer. It consists of tying the new shoots to the wires in proper position and of regulating the wood growth by pinching back shoots that tend to grow too long, taking out surplus shoots and shaping the vine generally. Three especial points should be kept in mind: The fruit-bearing shoots should be pinched back at the right time, the longer shoots which are being produced from the spurs should be given necessary attention to produce fruiting wood for the subsequent year, any surplus sprouts should be pinched out so they will not crowd those shoots which remain.

As has been mentioned each fruiting shoot will produce several clusters of fruit near its basal joints. If the vine is allowed to grow at will these fruit bearing shoots may continue to lengthen until they make too much wood growth. They may get so long and branch so much that the vine becomes too dense, shutting out sunlight so the fruit cannot 
mature well. They may even run along the trellis until they interfere with and tend to choke out adjoining vines. This is especially true of rank-growing varieties. If too much wood growth is allowed to form the vine may "run to wood" instead of properly developing its fruit. In order to prevent too much wood growth it is best to pinch back each fruit-bearing shoot when it has reached about three joints beyond the outer flower cluster. This pinching back will stop length growth of the shoot. As soon as length growth is stopped the shoot will become more stocky and better develop its fruit. Some of the shoots on the fruiting canes may fail to produce flowers and fruit. These barren shoots may be pinched out if they are numerous enough to crowd those which are bearing fruit. The fruit-bearing shoots may be tied to the wires, for support, so they will not break down. They should be arranged so they will not crowd each other.

It is important to take good care of the shoots which come from the short spurs, for they are to be the bearing wood for the subsequent season. They are usually trained up near the center, between the fruiting canes, and tied to the wires for support. They should be trained where they will get sunlight and not be crowded by other parts of the vine. Their welfare is of as much importance as is the welfare of the fruiting shoots themselves, for they are to renew the vine next year. When they reach the top of the trellis their tips should be pinched off to stop their length growth. Sometimes they will begin to lengthen again and will need a second pinching. Stopping their length growth makes them branch freely and become stocky and strong. They thicken faster and mature their wood better after length growth is stopped. By autumn they should be large and strong and for the most part well 
branched. If they set any flower clusters these should be pinched off. They should not be allowed to bear fruit, since all their strength will be needed for the fruit crop the next year.

A good many sprouts often start up from the roots of the vine. Surplus sprouts may start from almost any part of the old stem. All but two or three of these should be pinched off when it is seen in spring htat they will be in the way of the other parts of the vines. Some varietics sprout worse than others. If many sprouts are allowed to grow they will fill up the vine with too much wood growth and crowd and shade the fruit and the shoots which it is desired to save. The two sprouts that are saved are to be pruned as spurs the coming winter.

Sometimes a vine fails to grow in just the form one desires and one is sometimes confronted with the problem of putting a vineyard in shape which has been neglected. In such cases the vines may have long, old stems, due to neglect, and most of the bearing wood may be far removed from the base of the vine. In such cases one must cut the vine back judiciously and take a season or two to get it in the form described above. In cutting back it is best to remove as much of the vine as is possible and still leave some fruiting wood. The two lowest canes should be selected for fruiting canes and all the vine above should be cut away. If one cannot get good spurs below the fruiting canes he may induce the formation of sprouts below by twisting, or bending to one side the main stem. Shoots will come out just below the crook made in the stem. By cutting back as much as possible each season one may soon get the new growth back to a point near the ground. Cutting back in winter induces ranker wood growth and more abundant sprouts near the ground. 
In the drooping system much the same plan of renewing the vine is practiced as in the upright system. The vine is allowed to make a longer stem, however, and the spurs and fruiting canes are borne near the top of the trellis instead of near the bottom of it. One method of employing the drooping system is to use the same kind of trellis described for the upright system. The vine is allowed to produce a permanent stem which will reach to the top wire of the trellis. The two fruiting canes are then tied along the top wire of the trellis after the winter pruning. The fruiting shoots which are nroduced from the canes in spring will then hang Lownward from their weight. Two spurs for renewing the wood for the subsequent year are saved near the base of the fruiting canes. The method of pruning in winter is essentially the same as that already described for the upright system. The only difference is that in the drooping system the main stem of the vine is long enough so the fruiting canes and spurs are up near the top wire instead of down near the bottom wire.

The summer training of the drooping system is similar to the upright system except that the fruiting shoots hang down instead of being tied in an upright position on the trellis. The fruit-bearing shoots are pinched back when thev have reached about three joints beyond the last flower cluster. Sprouts which come from near the ground are kept pinched off in spring to maintain a bare stem up to the top wire. If for any reason this main stem ever becomes injured it may be renewed by allowing a sprout ta grow up from the roots of the vine.

Many growers who employ the drooping system of pruning prefer a different trellis from the one described above. Instead of having the wires run one above another on posts they prefer three wires, one 
strung along the row of vines, to which the fruiting canes are tied, and two wires, one on either side of the middle wire, supported by cross bars nailed to the tops of the posts. The posts are set so they will stand about four to six feet above the ground in the row. The cross bars are two and one-half to three feet long and fastened to the tops of the posts in a $T$ shape. The central wire, to which the pruned canes are tied runs through the posts just below the cross bar. The other two wires are strung along the ends of the cross bars so they come twelve or eighteen inches on either side of the central wire and about six inches higher than the latter.

As the fruit-bearing shoots are put out in spring from the canes tied to the central wire, they soon become long and heavy enough that they drop over the two side wires and hang down. About half the shoots are turned to one side and the other half to the opposite side, so half of them swing over each side wire. This spreads out the surface of the vine in a trough shape, the canes and bases of the bearing shoots being close to the central wire and spreading outward on either side so they hang over the two side wires. The clusters of fruit are borne near the bases of the new shoots so they hang down between the central wire and the side wires.

Certain other methods of training vines prevail in certain localities. In some instances special methods are devised to suit local or unusual conditions. For example, the writer has observed a method of training vines to a single post, in the Ozark region of Missouri. which is just suited to the conditions which prevail in some of the stony districts.

The method mentioned above is employed where the soil is so stony that hoeing weeds in the rows 
of plants is difficult. The stones, however, are mostly small, so cultivation with double shovel plows is $\epsilon$ asily done. It becomes desirable then to cultivate the vineyard both ways, in check rows, instead of only one way along the row. With this cultivation among the small stones they can keep the vineyard clean without hand hoeing. The grapes are set in squares, about ten feet apart each way, and each vine is trained to a single stake, set straight up at the base of the vine. This avoids the necessity of stringing wires and permits cultivation both ways.

In selecting the stakes some of the knots are left one or two inches long to act as pegs in supporting the vine when it is trained about the post. The vine is pruned to a single fruiting cane in some cases and in other cases to two fruiting canes. Each fruiting cane is bent outward and then toward the post at the top and tied there. The cane, described about the shape of an interrogation point (?), being tied to the post at the top of the curve and tied to it a second time eighteen inches lower down, where the tip of the cane is bent in to the post. The fruiting shoots hang down for the most part, though some of the lower ones are at times tied up to the lower part of the post or even to the curve of the main cane.

The method of pruning in this single post training is essentially the same as that employed in the up. right system. A short stem or short stump of the vine is allowed to grow year after year near the ground. The fruiting canes and spurs are renewed each year at the top of this short stem. Wood which has once fruited is pruned entirely away each winter.

Where the grape is grown to cover arbors or porches, where long branches are necessary to cover the top of the support, it may at times be necessary 
to allow long arms to grow perennially. In such cases it is well to allow the main stem to grow as high as is necesary to cover the arbor or porch in question and to train out from this as many fruiting canes each year as the space will permit. It is advisable also to prune to one spur near the base of each fruiting cane, so as to renew the fruiting cane, from this spur for the subsequent season. The) pruning and the summer training is similar in principle, then, to the trellis methods described above.

There is also a fan system of growing the vine which is sometimes employed. It is similar to the upright system first described. It differs from it only in that instead of leaving only two fruiting canes, from three to five canes are left at the time of winter pruning and a similar number of spurs for renewing the wood are also saved. The canes are spread out on the trellis like the ribs of a fan. One is trained straight upward from the center of the vine and the other canes are distributed equidistant on either side of this central cane.

\section{PRUNING BUSH FRUITS. \\ THE RED RASPBERRY.}

The wood of the red raspberry is biennial, that is, it grows up from the root as a long shoot or cane, and bears fruit on these canes the next season. The method of pruning is somewhat at variance among the different growers and in different parts of the country. Some growers practice summer pruning, in which the canes are pinched back to force out lateral branches, others allow the young cares to grow at will during the first season and cut back only during the winter.

Individually the growers all over the country are coming to doubt the advisability of the summer pruning of the red raspberries. Pinching back in 
summer seems to have the tendency of increasing the number of suckers thrown up from the roots. This overproduction of wood lessens the ability of the plants to produce fruit. The shortening of the leaders in early summer does not lead to the formation of strong vigorous side branches, but to weak branches which are subject to winter-killing. These side branches which are forced into the production of wood in early summer had best be allowed to remain dormant until the following spring when they will form good fruiting branches.

The experience of a large number of growers is that it is best to allow the red raspberry plantation to grow at will during the summer, and then during the winter or early spring cut all fruiting canes back to three, or in case of low-growing forms, to two feet of the ground. All old canes that bore truit the previous season should be removed at the ground at this time, as they are probably already dead, or if not will die before growth begins. Where the truiting canes are treated in this way they will throw out a large number of strong lateral branches in the spring which will produce all of the fruit that one cane ought to carry.

The only exception to the advisability of practicing summer pruning might be made in the case of very vigorous plantations, or especially rampant varieties. Whenever summer pruning is done it should be remembered that only the tender young tips should be pinched off with the thumb and Inger at a height of about eighteen inches from the ground. This will allow the lower buds to produce branches that can make their growth early in the season and become well ripened before winter. Summer pruning of the red raspberries is never practiced on the same scale that it is on the black varieties. 


\section{PRUNING BLACK RASPBERRIES.}

Like the red raspberry the black raspberrv has biennial wood and renews its cane from the roots. But instead of these new canes coming from suckers or stolons, they come from the base of the parent plant, as the black raspberry is essentially a hill or stool plant. New plants arise from roots formed at the tips of the branches when allowed to come in contact with the earth. With the black raspberry it always requires a great deal of careful summer pruning or pinching to make the canes stocky, and with a generous number of well-formed side branches. To force the black raspberries into the production of side branches, the new canes as they appear in the summer should have the tender young tips pinched out when the cane reaches a height of eighteen inches from the soil. The side branches will then be produced, and make a growth of several feet during the season. These branches as soon as they grow long enough to touch the ground, should be trained along the row where they will not be interfered with during cultivation, and where they may take root for the production of new plants. The black raspberry canes should never be allowed to get too high before pinching, and it is necessary to go over the rows several times during the summer and pinch the tips at the right time. Then plenty of side branches will be formed, strong canes will result, and the plants be in good shape to stand up well and produce a large crop of fruit. Clipping the laterals after they have grown to twelve or fifteen inches to make them branch again, has been recommended, but there is little if any advantage in it. It is only an additional expense and results in the production of a mass of small and poorly developed laterals, many of which will be winter-killed. 
During the winter or early spring, the general pruning of the plants must be done. In this operation all old canes, which bore a fruit crop the last season are to be cut close to the ground. All canes that are affected with anthracnose are likewise cut out and burned, leaving nothing in the rows but strong, well-developed new canes. These, if they were well pinched the last season, have branched well and resemble small trees. The laterals on these new canes are cut off so that the lowermost branches are twelve or eighteen inches long, those next above being shortened in slightly more, so that the canes after being pruned are pyramidal in outline. The side branches which had taken root at their tips, should be cut off just above the point where they are attached to the soil. This will leave a new plant to take the place of some old one that may be cut out entirely, or else make a new plant to be used in increasing the size of the plantation.

After pruning gather up all of the wood removed and burn it, being ezpecially careful to cut out and burn all canes having anthracnose.

\section{PRUNING THE BLACKBERRY.}

The blackberry resembles the red raspberry in habit of growth. The new wood comes from suckers and does not produce fruit until the second season, dying at the end of the season in which it produced a crop of fruit. As in the case of the black raspberry, summer pinching or pruning must be done. This work is practically the same as with the black raspberry, pinching out the tender young tip of the canes after reaching the height of about two feet, depending on the vigor of the variety. Some of the stronger-growing sorts need to be al. lowed to grow two feet high before being pinched, 
and all sorts will elongate considerably after being pinched back. The pinching-in is necessary to get a well branched cane, that will produce a good crop of fruit the following season, and it should be done by pinching out, with the fingers only, the tender young tip of the new cane. By allowing the canes to become four or five feet high and then cutting back to the desired height, side branches will not form so readily, and are not so fruitful, as if the tips are pinched earlier in the season.

The winter pruning of the blackberry is done in the same way as with the raspberries. Cut out all of the canes which have fruited. Leave nothing but strong young canes which will fruit the next season. Cut back the side branches to a foot or less in length, leaving the pruned cane somewhat pyramidal, or cone-shaped in outline.

\section{PRUNING THE CURRANT.}

Since the currant will usually produce some fruit no matter how treated, it frequently happens that no pruning at all is the case. The fruit is borne both on old and young wood, but principally at the base of the one-year-old shoots and on short-one-year-old spurs from the older wood. The old wood soon becomes weak and unproductive, while the younger wood produces the better fruit. The better plan, then, is to allow several young canes to form around the base of the plant each year, and at the pruning, which is best done in the early spring, remove all of the canes which are three years old. Shorten the more vigorous young shoots on the canes remaining. Sometimes the pinching-in of new shoots from the ground is practiced, making side branches form on the canes, but the method does not give universal satisfaction. In common practice, a liberal amount 
ot thinning out of old wood and shortening of the longer side branches is all that will be required.

\section{PRUNING THE GOOSEBERRY.}

This plant in habit of growth and fruiting character is much like the currant. On account of the thorns on the gooseberry it is apt to be allowed to become more filled up with old canes than the currant. However, these old canes should be removed after their value as fruit producers has passed, which is with the third year. Weak shoots that come up from the base should also be cut out entirely, or at least be shortened in to two or three buds. The significant thing with the gooseberry is to prune so as to renew the bearing wood, and have it always strong and vigorous. Ke $\epsilon \mathrm{p}$ the amount of wood reduced to the point at which the plant is able to supply it properly with food material, and not allow the center of the stools to fill up with old canes.

The gooseberry and currants in some parts of the country are trained into tree form. Only one cane is allowed to grow from the roots, and at a convenient height side branches are formed and kept trimmed so as to make a small tree-like head. While such piants are very ornamental, and produce a generous amount of fruit, they are liable to be attacked by borers or fungus, and as soon as the main stem is injured the whole plant dies. It is better in commercial plantings to allow a stool of shoots to develop. Where one or more are then attacked by enemies, other canes are at hand to renew the plant.

\section{PRUNING SHADE AND ORNAMENTAL TREES.}

In pruning shade trees it is easier to say don't than do. In apples and peaches certain specific facts cai be given in regard to pruning, but in shade 
trees it is much more difficult. As common as shade trees are, and as many tree-admirers as there are, it would seem as though the rudiments of pruning ought to be general knowledge. Yet a most casual olimpse at the shade and street trees decorating our city streets will reveal most painfully the fact that careful pruning is an unknown art to the general public. One does not have to be a lover of beautiful trees to see the devastation and ruin wrought by the "tree-butcher" as he chops and saws off the tops of our trees. "Trimming the trees," he calls it. But from the stubs left after the trees are "trimmed" one might better call it anything else.

It is rot a difficult undertaking to prune the shade trees properly. The general principles or most rudimentary facts regarding pruning are sufficient information in most cases. And where there are some especially fine trees, that the owner wants to have properly pruned, it would be best to call on some one who is competent to advise how to prune the trees correctly if this expert's services cannot be obtained to actually do the work. Trees differ so greatly in habit of growth that it is not possible to lay down positive directions for pruning. However, certain general factors in the work may be given.

Begin with the young tree. Have the tree carefully planted in good soil Shape the tree when it is cet, so that in subsequent years it may develop its form naturally. This shaping is done in the same manner as given for the apple. Leave first of all a strong limb in the center for the leader, and make all other branches subordinate to that. If there are two or more branches struggling for the central position in the tree. cut one off entirely or at least shorten it in to a few buds in length. If it is cut entirely off, make the cut close to the body of the tree so that the wound formed will heal over quickly. 
Avoid leaving a short stub wherever it is necessary to remove a branch. Make the cuts close to the body of the tree, since by doing so the healing over of the wound will be done more quickly, and rot not be so apt to start in the trunk. The lateral branches on the young tree to be planted should be so cut that the outline of the pruned tree will be cone-shaped. In each season after the tree is planted some pruning should be done. It may be necessary to remove only a few whips each season. In fact, if the tree is properly cared for a heavier instrument than a pocket knife is never needed. But there are few trees indeed which are so carefully pruned!

It is seldom that the shade trees are thought of as needing pruning till they have become quite mature, then the man-of-all-work is called in and told to "trim them up." Since this individual usually knows nothing of the correct way of pruning the trees it happens that the entire top is removed and nothing left. That method of pruning cannot be too strongly condemned. It results in ruined trees. A mass of sprouts will come from the stubs which are left, and in the course of only a few years these. shoots will be struggling with each other for the central position in the tree. The cutting back has interrupted the shape the tree had originally formed, and nothing can be done atterwards to get it back. When the head of the trees become large and make too much shade in the door yard, don't cut their heads off! Shorten back the longest branches to a strong branch lower down, and on this side branch, if it is too long, shorten it back in the same way. Always cut back to a side branch, and make the cut in such manner that the wound will heal over most quickly. This will usually be done by making the cut start in the angle formed with the side 
branch and letting it follow through the limb to be removed in the same direction as the side branch to be left. The side branch will then stand on the highest point of the cut. The new wood which will cover over the wound will then have the most direct flow, and a few seasons' growth will cover the wound completely. In case the limb to be removed is very large and there is danger of its splitting and tearing off a strip of wood from the lower part of the limb, it is best to saw the limb off in two places. This is done by making the first cut a foot or more above the point at which it is desired to remove the limb. Begin on the under side of the limb and cut half way through. Then saw the limb off from above, making the second cut just above the first one. The heavy portion of the limb will then have been removed and there will be no danger in subsequent cutting of tearing the wood or bark by the fall of the top. After the top of the limb is removed, cut the stub off at the proper place, sawing from above or below as may be most convenient. In case of very large limbs it will be safest to always begin the sawing upon the lower side. In case the limb should fall, there will not be so much possibility for it to split the trunk. Some few days after removing a large limb, after the surface of the wound has dried, give it a thick coat of linseed oil paint. White lead and linseed oil is the best material to use, and it may be tinted any shade desired, to match the bark of the tree. Put on a thick coat of this paint to cover the wound and keep out water and germs of rot fungi and bacteria.

In shortening in these limbs, leave the strongest and most central one for a leader and make all others subordinate to it. When trees are so shaped there is not so much danger of their being broken to pieces or badly split in severe wind or ice 
storms. It is possible for one who is skilled in pruning to make a fairly well-shaped tree from one which is badly forked, but it is easier to have beautiful old trees if they are properly cared for and kept beautiful while they are young.

The character of the tree and the purpose to which it is put determines to some extent the form which it must be given in pruning. For trees such as the Pin Oak. Sycamore, Hard Maple. Pines and Cypress, it is difficult to keep a central leader from being formed, and difficult to make other than a coneshaped tree. The natural form of growth is with a strong central trunk with all the branches arising from it. In others, as the Silver Maple, Elm, Box Elder, Walnut, Coffee Bean and some of the Oaks, the natural habit is with an open spreading top, with no well-defined center. In such trees it is difficult to maintain a leader, although it is not impossible in all of them. For those trees, whose wood is tough and strong enough to withstand the strain of a wind storm without breaking, the natural habit may be allowed, but for those whose forked branches are split and twisted in the storms it is best to arrange the branches in such manner as will best withstand the strain put upon them. The American Elm is one of our most beautiful trees, yet one which will develop only a wide-spreading top, giving the outline the symmetry of a gracefully molded vase. Fortunately nature has provided this magnificent tree with a tough cross-grained wood difficult to split. Its long $Y$-shaped arms can withstand the most severe gales without splitting. On the other hand, the Silver Niaple, ur.less most carefullv shaped, will split badly on the slightest provocation. This is somewhat unfortunate perhaps, because it is of rapid growth and is extensively planted as a yard and street tree. And in the greater majority of cases 
the trees at the time of planting could have been so pruned that most of the splitting would have been avoided.

\section{PRUNING SHRUBS.}

It is a hopeful sign in American gardening to see an increasing number of our native shrubs planted for home decoration. Our climate is well adapted to the growth of flowering shrubs, and when we learn to give them deep rich soil, fertilize and cultivate them well and prune them properly much more will have been done to improve the appearance of the home ground By far the least understood art in the handling of decorative shrubbery is that of properly pruning them. It is easier to tell what not to do than it is to tell what to do, and it is still easier to show how to prune the various shrubs than it is to tell how. The most cruel way in which flowering shrubs can be treated is to turn the man-of-all-work loose on them with a pair to pruning shears and the instructions to "trim them into shape." This will usually result in all of the shrubs being sheared off into an even shape, or carved into various geometrical figures, all of which are entirely the opposite of what is desired in the plan of growing usually practiced in this country.

In America the principal style of planting is that which follows the style taken by wild plants growing under the care of nature, where each plant is allowed to develop according to its own individuality. In a shrubbery border about the home grounds then, each shrub should be allowed to develop its special graces in the line of its natural growth. This cannot be done by cutting back all of the branches on the plant to an even length, or trimming into formal shapes. This shearing not only destroys the natural beauty of outline of the shrub, but lessens its 
ability to produce flowers and fruit and weakens its constitution.

There are two or three elementary rules to be observed in the pruning of shrubs where the produc tion of flowers is desired. Those shrubs which blossom early in the spring form their flower buds the year before, and these buds may be seen on the slender branches of the plant at any time during the winter. The removal of these branches during the winter, then, means that there is danger of removing the flowers, and there will be no blooms in the spring. If, however, the branches are cut back in the summer after the flowering season is over, the growth of new shoots will be encouraged and a larger setting of flower buds obtained. This will make the shrubs take on a much more decorative appearance in the spring than if the pruning is postponed till the following winter or spring.

Those plants which flower in the middle or latter part of summer, such as the Altheas, Tamarisks and Hydrangeas, should have their pruning done in the late fall or early spring before the buds start. The flowering wood, in these cases the flower buds, are formed on the wood grown during the current summer, and the removal of the wood during the early part of the season encourages the growth and development of strong wood and well-nourished flower buds. Shrubs are not grown principally for their flowers, but for their beauty throughout the entire year. For the amateur who has had no experience in pruning shrubs it might be suggested that the plants be pruned after they have flowered. But how is this pruning to be done? Let us see.

We must remember that pruning is done for several purposes, none of which must be sacrificed for the other. We prune to keep the shrubs within bounds and to prevent their overcrowding their 
neighbors; also to keep the bushes in proper shape for the production of flowers. As a general statement it may be said to remove all wood which has produced flowers, cutting either in the spring or summer, as may be necessary. New flowering wood is then formed for the next season's crop. And in this removal of old wood, any which is weak or dead or rubbing another branch should be removed at the same time. Cut back any branches which have borne a crop of flowers to a strong young shoot or back to the ground. Allow all strong new canes from the ground to develop, and shorten in slightly any side branches that may have formed on the new canes, or which were left on the older canes.

\section{PRUNING FOR SPRING FLOWERS.}

Among the common spring flowering shrubs are the Spireas, Lilac, Deutzias. These and all other spring-flowering shrubs should have their pruning done in early summer just after the flowering period has passed. In the Spireas cut away all of the old wood close to the ground, and if the stool is large, thin out some of the center canes, which are weak and not well clothed with either leaves or flowers. This may mean that quite a large proportion of the shrub may need to be cut out, especially if the shrub has not been pruned for some seasons. If the plant has had its top sheared to an even length on all of the canes, remove all of the largest canes, which have produced several small shoots near the top. Allow the strongest of the young canes coming up from the roots to grow their full length and bend or branch as they may be inclined. The removal of all of the old sheared canes will then allow the shrub to renew its natural symmetry and grace, and form its profusion of blooms in a more becoming manner. It very often happens 
that the best manner to renew a plant which has been sheared into some formal shape is to cut all: of the canes off even with the surface of the soil. All new canes which then develop are allowed to make growth as they will. The subsequent pruning can then be done in the proper manner more easily than where the shrub is renewed by the partial removal of the sheared canes. This process, however, causes the loss of the flowers for one or two seasons and may make the shrubbery border look bleak and bare for at least one winter season following the pruning. But the bushes will break awa freely and form dense, handsore bushes and flowers so freely the following season that the loss of one crop of flowers will be forgotten. It is needless to say that the removal of all of the canes must be done in the winter or early spring in order to get a renewal of the canes. If done in the summer when the plants are in full leaf there is danger of killing the entire plant, or at least lowering its vitality to a great extent. This is because the food substance stored up in the roots has nearly all passed up into the branches to be used in the production of flowers and new wood, and little is left in the roots to push out new canes from the roots. While if the pruning is done in the winter or early spring all of the food material in the roots will pass into new growths trom the roots and the plant be entirely renewed with strong new canes the first summer.

\section{PRUNING FOR SUMMER FLOWERS.}

Plants which produce their flowers in the late summer bear those flowers on the wood which formed during that summer. Naturally then the pruning of those shrubs should be done in the early spring before the growth starts. For example, the 
large panicled Hydrangea may be cut back in the fall or eariy spring to a couple of buds on each annual shoot. A very vigorous growth will result. Many of the branches which start will be in the center of the plant, where they will be crowded and shaded so that only a weak branch will be formed. These should be pinched out early in the summer and allow all of the growth to be made in the stronger shoots. All of the strong branches formed during the season will bear a well-developed flower head at its extremity so that the entire bush is well clothed with bloom in late summer.

It should not be forgotten, though, that too much pruning weakens plants. The forcing of the energy of the plants into the production of flowers reduces the vitality, and a heavy crop of flowers in any one season may result in a small production of flowers during the next season. To those who watch closely the growth of their plants this will soon be apparent and due allowance can be made for the production or flowers or the shape of the plant. No specific rules can be laid down to be followed to the letter in the matter of pruning ornamental shrubbery. Much depends on the individual plant and on the caretaker. Close observation of the habits of the various plants will soon instruct one as to what to do and what to not do. The best way to prune shrubs is purely a matter of experience; what may do for one person or one shrub may not do at all for another.

\section{THE HEALING OF WOUNDS.}

It is easily observable to all those associated with trees that wounds made in pruning sometimes heal directly, leaving no injury to the tree, and that on the other hand they sometimes fail to heal well, decay may set in, and the tree may count the begin- 
ning of its untimely death from the formation. of this wound in pruning. It is well to bear in mind that the healing of wounds bears relation to three important points: The season when the cut was made, the way in which the operation was performed and the treatment which was given the wound, or often more properly, the treatment which was neglected.

As to the season when pruning may be done so the wounds will heal most rapidly, it may be said in a general way that wounds heal most readily if they are made when growth of the tree is most rapid. This is usually in the spring after length growth of the tree is well under way. In fact it is sometimes about the first part of the summer. Wounds properly made at that time usually close over in a short time, especially if they are not large. The cone-bearing trees which exude much pitch heal decidedly better if pruned at the beginning of summer. If they are cut in the winter the wounds exude much pitch, which fills the wound and often hardens so the new growing layer cannot well cover it. If wounds are made when the tree is frozen they are likely to check and dry out so much that rot may set in before they can heal the following. summer. If pruning is done on warm days in winter or early spring, when the wood is not frozen, the wounds will not heal of course until after growth begins in the spring, but if they are properly attended to there is no reason why they should not heal without decay when summer does come. If pruning is done at that season in spring (varying with different species), when the wounds will bleed, or exude sap, the wounds may fail to heal on account of organisms of decay starting in this sap, when perhaps they would not have gained entrance to the wood if it had not been for this sap. 
A wound heals most readily if it is cut so the growing layer of the tree can close over it. That is, if a limb is being removed it should be cut close to the body of the trunk or larger limb from which it is being removed. No knot should be left. Where such a limb is removed one must rely upon the growing layer of the tree to close over the wound. The growing layer is between bark and wood. If a knot is left its growing layer dies back to the body of the tree from which the limb was cut. This means that the knot which is left will die and the tree cannot close over it until its diameter increases sufficiently to press out beyond the entire knot. This may take years. If the limb is cut close, so no knot remains, the growing layer will begin to close over the wound as soon as growth begins. If the cut is made during the growing season the wound will immediately begin to heal. If the wound is not large the wound will heal in a single season. It makes a larger wound to cut a limb close than it does to cut it farther out, leaving a short knot, The larger wound will heal more quickly, however, because there is no knot there to hold the growing layer from closing over the wound.

The treatment of wounds is important. First, the cutting should be done with a sharp instrument, so the wound will not be ragged. If a saw is used it should be sharp and handled so as to make a smooth cut. If a knife is used the same precaution should be taken. A smooth wound, which leaves a smooth, uninjured line of growing layer will heal better than a ragged wound. The wound should be treated if it is more than one-third of an inch in diameter. The best treatment is to cover it with something which will preserve the wood. To preserve the wood means to keep it from decaying. If decay sets into the wound it may run down into the tree 
and injure it before the wound can heal over. White lead paint and oil, such as would be used on the weather boards of a building, is about as good as anything with which to dress wounds. It preserves wood. In preserving the wood of a wound it accomplishes just what it does in preserving the wood of a house. Preventing decay of the wound favors its healing. A wound should be painted as soon as the surface of the wood dries after the cut is made. If the weather is pleasant the paint should be put on the next day after the wound is made. If the wound is large two coats of paint should be applied, just as two coats are necessary to keep the wood of a house from decay. The first coat should be allowed to dry a day or two and the second coat should be applied.

If trees have been neglected and any wounds, made by improper pruning or by breaking of limbs, are seen at any time they may be corrected by shortening the knot, or any dead parts, and painted so they will heal more readily. In cutting back a branch the wound will heal more readily if one cuts back to a vigorous side shoot, so that this growing shoot will terminate the limb after it is shortened. If one cuts back to a bare stub, which is terminated by no growing shoot, the stub will die back to the first growing shoot below. 


MAY 49906 
LIBRARY OF CONGRESS



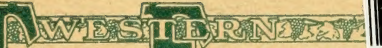
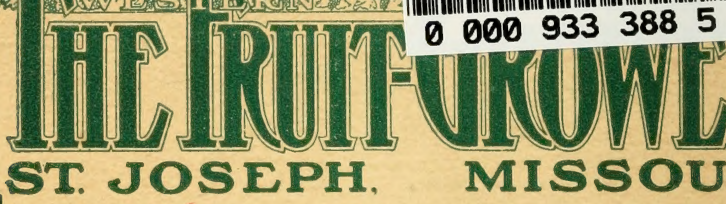

00009333885

America's Leading Horticultural Paper

Published Monthly - Send For a Free Sample Copy

\section{One Dollar a Year=Three Years $\$ 2$}

One "Brother Jonathan" Book Free with every remittance of $\$ 1.00$ on subscription

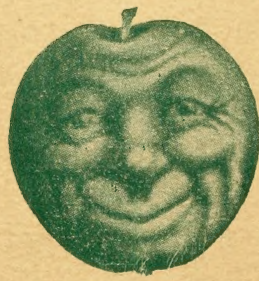

"Brother Jonathan"

Trade Mark of The Fruit-Grower

St. Joseph, Mo. 